\title{
Combination chemotherapy of S-1 and taxanes in Korea
}

\author{
Yeul Hong KIm ${ }^{1}$ and Hoon-Kyo KIm ${ }^{2}$ \\ ${ }^{1}$ Department of Internal Medicine, Korea University, College of Medicine, 126-1 Anam-dong 5 ga, Sungbuk-gu, Seoul 136-705, Korea \\ ${ }^{2}$ Department of Internal Medicine, St. Vincent's Hospital, The Catholic University of Korea, Suwon, Korea
}

\begin{abstract}
Various combination treatments incorporating S-1 are undergoing clinical trials in Korea, especially combinations with taxane, oxaliplatin, or irinotecan. In a phase I study to estimate the maximum tolerated dose of docetaxel in combination with S-1 administered at a fixed dose of $40 \mathrm{mg} / \mathrm{m}^{2}$ twice daily on days 1-14 of each 3-week cycle in patients with advanced gastric cancer, $60 \mathrm{mg} / \mathrm{m}^{2}$ docetaxel was declared to be the maximum tolerated dose. A phase I/II study of the same schedule of combination chemotherapy with S-1 plus docetaxel reported doses of $S-1 /$ docetaxel of $40 / 75 \mathrm{mg} / \mathrm{m}^{2}$ as the maximum tolerated dose. In a phase I study of S-1 plus weekly docetaxel, the patients received variable doses of docetaxel administered intravenously over $1 \mathrm{~h}$ on days 1 and 8 and S-1 administered on days 1-14 of each 3-week cycle. The maximum-tolerated doses of $\mathrm{S}-1$ and docetaxel were determined to be $45 \mathrm{mg} / \mathrm{m}^{2}$ and $35 \mathrm{mg} / \mathrm{m}^{2}$ in this study. A phase I/II study of docetaxel plus $\mathrm{S}-1$ combination chemotherapy from Korea reported a response rate of $43.3 \%$. Also, a phase II study of paclitaxel plus $S-1$ as first-line therapy in patients with advanced or relapsed gastric cancer showed an overall response rate of $49 \%$. The most frequent significant toxicities in combination chemotherapies with taxane plus S-1 were neutropenia and febrile neutropenia. However, nonhematological toxicities were mild to moderate. A taxane plus S-1 combination regimen could be a new standard regimen for advanced gastric cancer, given its significant activity and favorable toxicity pattern.
\end{abstract}

Key words Gastric neoplasm - Docetaxel - Paclitaxel · S-1 · Combination chemotherapy

\section{Introduction}

Although the incidence and mortality rates of gastric cancer are decreasing on a worldwide basis, Korea

Offprint requests to: $\mathrm{Y}$. $\mathrm{H}$. Kim

Received: January 7, 2008 / Accepted: April 24, 2008 continues to have one of the highest incidence rates of gastric cancer [1]. According to the Korea Central Cancer Registry and Local Cancer Registries data, gastric cancer remains the leading malignancy in both sexes, although its incidence has decreased slightly [2]; the age-standardized incidence rate for gastric cancer was 58.6 per 100000 for males and 30.8 per 100000 for females from 1999 to 2001 [2]. Surgical resection is the only therapeutic modality capable of cure, and improvements in early diagnosis, preoperative assessment, and surgical techniques have increased the number of potentially curative resections over the past 20 years. However, despite these improvements, prognosis remains poor, with overall 5-year relative survival rates of approximately $20 \%$ in most areas of the world, except for Japan [3].

The reasons for this grim outlook are that both local and distant relapse, even after apparently complete resection, are common, and that many patients present with inoperable disease at the time of diagnosis. In such patients, chemotherapy is one of the main treatment strategies that are employed. Although previously it was not clear whether chemotherapy contributed to the survival of patients with unresectable advanced gastric cancer, recent studies that have compared patients who received chemotherapy with non-chemotherapy-treated patients (best supportive care; BSC) have demonstrated that chemotherapy improves survival in advanced gastric cancer [4-6].

The treatment of advanced gastric cancer in Korea has followed the leads given in the reports published in and the experiences of practitioners in other countries. In the 1980s, the 5-fluorouracil (5-FU), adriamycin, and mitomycin (FAM) regimen was adopted as a standard chemotherapy, and until the mid 1990s, clinical trials conducted in gastric cancer patients in Korea mainly replicated well-known therapeutic regimens or modified original protocols to improve toxicity profiles. 


\section{Clinical results of taxane use in Korea}

Taxanes have been actively investigated in the context of gastric cancer chemotherapy in Korea, and the combination of paclitaxel, cisplatin, and 5-FU appears to be highly active, with acceptable toxicity [7], with an overall response rate of $51 \%$ and a complete response rate of $10 \%$ being achieved in 41 patients with advanced gastric carcinoma. Moreover, the combination of paclitaxel, infusional 5-FU, and leucovorin showed a response rate of $31.7 \%$ and a median survival of 60 weeks in 60 patients with advanced gastric cancer [8]. Promising results were also reported for various doses and schedules of paclitaxel and cisplatin, with overall response rates of $36.5 \%$ to $44 \%$ and median times to progression and overall survivals of 4.7 to 6.0 months and 10.8 to 12.1 months, respectively $[9,10]$. In addition, paclitaxel plus carboplatin had a response rate of $22 \%$ in patients with advanced gastric cancer previously treated with 5FU and platinum [11]. One study compared paclitaxel plus 5-FU with docetaxel plus 5-FU as first-line chemotherapies in patients with metastatic gastric cancer [12]. Although no significant difference was found in terms of their therapeutic efficacies, paclitaxel plus 5-FU was found to be associated with fewer grade 3 or 4 toxicities and a better quality of life [12].

Docetaxel (Taxotere; Sanofi-Aventis, Paris, France) is a semisynthetic taxoid derived from the European yew tree, Taxus baccata [13]. Docetaxel has more potent activity than the natural taxane paclitaxel in terms of the stabilization/hyperplasia of microtubules by facilitating microtubule protein polymerization, thereby inhibiting mitosis to display antitumor effects [14]. Docetaxel has shown encouraging activity in gastric cancer; the singleagent response rate ranged from $17 \%$ to $24 \%$, with a mean of $19.1 \%$ ( $95 \%$ confidence interval $[\mathrm{CI}] ; 14.3 \%-$ $23.8 \%$ ) [15]. Docetaxel at $75 \mathrm{mg} / \mathrm{m}^{2}$ produced a response rate of $15.9 \%$ in Korean gastric cancer patients [16]. Interestingly, the response rate of docetaxel monotherapy was similar in chemotherapy-naïve and previously treated patients [17]. Several investigators have tried docetaxel plus cisplatin in patients with advanced gastric cancer, and achieved overall response rates of $17.1 \%$ to $43.5 \%$ and median survivals of 5.8 to 11.5 months [1820]. Based on a synergism between docetaxel and 5-FU found in a preclinical study, docetaxel was administered with infusional 5-FU and low-dose leucovorin to 66 patients with advanced gastric cancer. A response rate of $34.2 \%$ was achieved in chemonaive patients and the rate was $14.2 \%$ in previously treated patients [21]. Various doses and combination schedules of docetaxel and capecitabine have also been examined in advanced gastric cancer. In a weekly docetaxel plus capecitabine trial, 55 patients received docetaxel $\left(36 \mathrm{mg} / \mathrm{m}^{2}\right.$ intravenously), on days 1 and 8 , and capecitabine $\left(1000 \mathrm{mg} / \mathrm{m}^{2}\right.$ orally twice per day), on days $1-14$, in a 3 -week schedule until progression occurred. The overall response rate and median survival were $40.4 \%$ and 12.0 months, respectively [22]. On the other hand, when docetaxel was administered every 3 weeks at $75 \mathrm{mg} / \mathrm{m}^{2}$ with capecitabine at $1250 \mathrm{mg} / \mathrm{m}^{2}$ twice daily on days $1-14$, the response rate was much higher $(60 \%)$, with a median survival of 10.5 months [23]. However, this combination treatment showed high incidences of stomatitis and hand-foot syndrome as dose-limiting toxicities, which prevented continuous treatment. When the capecitabine dosage was reduced to $1000 \mathrm{mg} / \mathrm{m}^{2}$ in this regimen, the response rate fell to $43.8 \%$, while the reduced capecitabine dosage reduced the incidence of hand-foot syndrome [24]. The phase III TAX 325 study, which enabled the registration of docetaxel in combination with cisplatin and intravenous 5-FU in Europe and the United States, demonstrated a superior response rate, time to progression, overall survival, clinical benefit, and quality of life over cisplatin and intravenous 5-FU in patients with advanced gastric cancer, and thus clearly demonstrated both the activity of docetaxel in this disease, and also the proof of principle of the benefit of adding docetaxel to standard regimens [25].

\section{Clinical results of S-1 use in Korea}

S-1 (Taiho Pharmaceutical, Tokyo, Japan) is an oral fluoropyrimidine derivative that combines tegafur with two modulators of 5-FU metabolism, 5-chloro-2, 4dihydroxypyridine (gimeracil) and potassium oxonate (oteracil), in a molar ratio of 1:0.4:1. Tegafur, an oral prodrug of 5-FU, is gradually converted to 5-FU and rapidly catabolized by dihydropyrimidine dehydrogenase (DPD) in the liver. Gimeracil inhibits the degradation of 5-FU by the inhibition of DPD. Oteracil is an orotate phosphoribosyl transferase (OPRT) inhibitor, which preferentially localizes in the digestive tract. This component of S-1 decreases the phosphorylation of 5$\mathrm{FU}$ in the gastrointestinal mucosa and reduces the incidence and severity of diarrhea [26]. Phase II studies of S-1 monotherapy in patients with advanced gastric cancer showed overall response rates of $26 \%-49 \%$, with the most relevant adverse effects being diarrhea in a European study and neutropenia in two Japanese studies [27-29]. Although a phase II study of S-1 alone produced a response rate of only $19.3 \%$ in Korea [30], which was much lower than that reported in Japan (44\%-49\%), an S-1 plus cisplatin combination demonstrated a response rate of $48 \%$, with a favorable toxicity profile [31]. Various combination treatments incorporating S-1 are undergoing clinical trials in Korea, especially combinations of S-1 with a taxane, oxaliplatin, or irinotecan. 


\section{Combination chemotherapy of S-1 and taxanes in Korea}

Docetaxel and S-1 have different modes of action and are highly synergistic in gastric cancer xenografts [32]. Also, the synergistic effects of docetaxel and S-1 were evident both in vivo and in vitro and could be explained by docetaxel's biochemical modulation of the expression and activity of the thymidylate synthase (TS), DPD, and OPRT enzymes, which play key roles in the functional activities of $5-\mathrm{FU}$ or S-1 [33]. The docetaxel/S-1 combination was active and well tolerated in phase I studies, a phase I/II study, and a phase II study in advanced gastric cancer, although the treatment schedules were slightly different [34-38]. The result of a recent phase II study in [38] patients with advanced gastric cancer (docetaxel $40 \mathrm{mg} / \mathrm{m}^{2}$ administered intravenously over $1 \mathrm{~h}$ on day 1 and oral S-1 administered at a fixed dose of $40 \mathrm{mg} / \mathrm{m}^{2}$ twice daily on days 1-14 of each 3-week cycle) was highly promising (a response rate of $56.3 \%$ with a median survival time of 14.3 months), with tolerable toxicities; accordingly, a multinational randomized phase III study comparing S-1 alone versus docetaxel plus S-1 was planned at this dose and schedule. The relatively low dose of docetaxel recommended in that study, possibly as a result of the conservative definitions used for dose-limiting-toxicities (DLTs) in the previous phase I study [37], (i.e., the DLTs were mild compared with the definitions used in other phase I studies) [37] resulted in the need to conduct a further dose-finding phase I trial of the docetaxel and S-1 combination.

Investigators from St. Vincent's Hospital and Korea University Anam Hospital conducted a phase I study for the escalation of docetaxel with a fixed dose of S-1 in advanced gastric cancer [39]. The primary endpoint of this study was the determination of 3-weekly docetaxel dose feasibility in the combination of docetaxel and oral S-1 administered at a fixed dose of $40 \mathrm{mg} / \mathrm{m}^{2}$ twice daily on days 1-14 of each 3-week cycle in patients with advanced gastric cancer. Between October 2004 and June 2005, 13 patients from the two institutes were enrolled in this study. Patients received variable doses of intravenous docetaxel administered intravenously over $1 \mathrm{~h}$ on day 1 and oral S-1 administered at a fixed dose of $40 \mathrm{mg} / \mathrm{m}^{2}$ twice daily on days $1-14$ of each 3week cycle. Three doses of S-1 were established according to body surface area (BSA;BSA $<1.25 \mathrm{~m}^{2}, 80 \mathrm{mg} /$ day; $1.25 \mathrm{~m}^{2} \leq \mathrm{BSA}<1.5 \mathrm{~m}^{2}, 100 \mathrm{mg} /$ day; and $1.5 \mathrm{~m}^{2} \leq \mathrm{BSA}$, $120 \mathrm{mg} /$ day). The initial starting dose of docetaxel was $40 \mathrm{mg} / \mathrm{m}^{2}$ (dose level 1), and stepwise dose increases to 50,60 , and $70 \mathrm{mg} / \mathrm{m}^{2}$ were planned for successive patient cohorts (dose levels 2, 3, and 4, respectively). DLTs were defined as follows: (1) grade 3 febrile neutropenia (absolute neutrophil count $<1000 / \mu l$ with fever $\geq 38.5^{\circ} \mathrm{C}$ ); (2) grade 4 neutropenia lasting for 7 days or longer; (3) grade 4 thrombocytopenia or thrombocytopenic bleeding; (4) grade 3/4 nonhematological toxicities other than nausea/vomiting and alopecia.

Initially, 4 patients were allocated at dose level 1 (docetaxel $40 \mathrm{mg} / \mathrm{m}^{2}$; first cohort of level 1). However, 1 patient dropped out after the first cycle of treatment due to violation of eligibility criteria. The 3 other patients at dose level 1 did not experience DLT. Therefore, the dose of docetaxel was increased, and the initial 3 patients at dose level 2 (docetaxel $50 \mathrm{mg} / \mathrm{m}^{2}$; first cohort of level 2) were enrolled. One patient in this cohort developed grade 3 elevation of alkaline phosphatase and another patient had prolonged grade 4 neutropenia. To evaluate toxicity in a larger group at dose level 2, 3 additional patients were enrolled (second cohort of level 2). No patient in this cohort developed DLT. Thus, 2 of 6 patients at dose level 2 developed DLT and the initial 3 patients at dose level 3 (docetaxel $60 \mathrm{mg} / \mathrm{m}^{2}$; first cohort of level 3) were enrolled. All 3 patients at this dose level developed DLT ( 1 with grade 4 metabolic acidosis; 1 with grade 3 gastrointestinal hemorrhage; and 1 with grade 3 febrile neutropenia, grade 3 mucositis, and grade 3 diarrhea), and this level was declared to be the maximum tolerated dose (MTD). Hence, level 2 (docetaxel $50 \mathrm{mg} / \mathrm{m}^{2}$ ) was declared to be the recommended dose (RD) for the next study. As 9 of the 13 enrolled patients responded to treatment, the overall objective response rate was $69.2 \%$ (95\% CI, $44.1 \%-94.3 \%$ ).

Grade 4 neutropenia occurred in two of four patients at docetaxel $40 \mathrm{mg} / \mathrm{m}^{2}$, in four of six patients at docetaxel $50 \mathrm{mg} / \mathrm{m}^{2}$, and in one of three patients at docetaxel $60 \mathrm{mg} / \mathrm{m}^{2}$. Grade 3 and grade 4 thrombocytopenia developed in one patient at $40 \mathrm{mg} / \mathrm{m}^{2}$ and in one patient at $60 \mathrm{mg} / \mathrm{m}^{2}$ of docetaxel, respectively. Grade 3 or 4 anemia was also noted in two of four and two of three patients at $40 \mathrm{mg} / \mathrm{m}^{2}$ and $60 \mathrm{mg} / \mathrm{m}^{2}$ of docetaxel, respectively. The main nonhematological toxicities encountered were anorexia, abdominal pain, nausea/vomiting, abnormal hepatic function, and infection without neutropenia. Most nonhematological toxicities were of mild to moderate intensity. Grade 3 nonhematological toxicities were observed in five patients (diarrhea and infection without neutropenia in two patients each and one patient with nausea/vomiting).

Zang et al. [40] conducted a phase I/II study to define the maximum tolerated dose (MTD) and recommended dose (RD) of the same schedule of S-1 plus docetaxel combination chemotherapy as that used in the study above [39] in patients with advanced or recurrent gastric cancer. Patients received variable doses of intravenous docetaxel administered intravenously over $1 \mathrm{~h}$ on day 1 and oral S-1 administered at variable doses twice daily 
on days 1-14 of each 3-week cycle. Each cohort of 3 patients was treated with escalating doses of S-1/ docetaxel at $30 / 60 \mathrm{mg} / \mathrm{m}^{2}$ (level 1), $40 / 60 \mathrm{mg} / \mathrm{m}^{2}$ (level $2 \mathrm{~A}$ ), $30 / 75 \mathrm{mg} / \mathrm{m}^{2}$ (level $2 \mathrm{~B}$ ), and $40 / 75 \mathrm{mg} / \mathrm{m}^{2}$ (level 3 ). A total of 56 patients were enrolled in this study (15 patients for the phase I study, 6 for a phase I study of elderly patients, and 35 for the phase II study). At level 3,2 of the 3 enrolled patients developed DLTs (grade 4 febrile neutropenia and grade 4 neutropenia with grade 3 stomatitis, respectively). Therefore, level 3 and level 2B were declared to be the MTD and RD, respectively. However, 2 patients (aged 66 and 64 years) developed fatal toxicities during the initial phase II study. Zang et al. conducted an additional phase I study for elderly patients (age, more than 60 years) with level 2A and no DLTs occurred at this level. Hence, level 2A was determined as the RD for elderly patients. The response rate of the phase II study was $43.3 \%$ ( $95 \%$ CI, $26 \%-61 \%$ ). The most common grade $3 / 4$ toxicities were neutropenia $(41.1 \%)$, leucopenia $(35.7 \%)$, and febrile neutropenia $(26.8 \%)$.

Park et al. [41] conducted a phase I study to define the MTD and DLT of S-1 plus weekly docetaxel in patients with metastatic gastric cancer. Patients received variable doses of docetaxel administered intravenously over $1 \mathrm{~h}$ on days 1 and 8 and oral S-1 administered at variable doses twice daily on days 1-14 of each 3-week cycle. Each cohort of 3 patients was treated with escalating doses of S-1/docetaxel at $30 / 25 \mathrm{mg} / \mathrm{m}^{2}$ (level 1), $35 / 25 \mathrm{mg} / \mathrm{m}^{2}$ (level 2), $35 / 30 \mathrm{mg} / \mathrm{m}^{2}$ (level 3), $40 / 30 \mathrm{mg} / \mathrm{m}^{2}$ (level 4), $40 / 35 \mathrm{mg} / \mathrm{m}^{2}$ (level 5), $45 / 35 \mathrm{mg} / \mathrm{m}^{2}$ (level 6), and $45 / 40 \mathrm{mg} / \mathrm{m}^{2}$ (level 7). A total of 222 cycles of treatment were administered to 30 patients. At dose level 1, one of the first 3 patients experienced a DLT (grade 3 aspartate aminotransferase [AST] elevation), but none of the 3 additional patients experienced a DLT. During dose escalation, DLT did not develop until dose level 7, at which 2 of 3 patients experienced DLTs (grade 3 febrile neutropenia and grade 3 infection with neutropenia with grade 3 stomatitis/anorexia). Therefore, the next 3 patients were entered at dose level 6 , but 2 of these patients ( 2 of a total of 6) had DLTs (grade 3 diarrhea with grade 3 fatigue and febrile neutropenia with grade 3 anorexia/fatigue). An additional 3 patients were entered at dose level 5, but 1 ( 1 of a total of 6 ) experienced a DLT (gastric perforation at the tumor site on the first day of cycle 1). Hence, the MTD and RD of S-1 plus weekly docetaxel were determined to be $45 / 35 \mathrm{mg} / \mathrm{m}^{2}$ (level 6) and $40 / 35 \mathrm{mg} / \mathrm{m}^{2}$ (level 5), respectively, in this study.

The result of a phase II study of this regimen was reported in 2007 at the American Association for Cancer Research Annual Meeting [42]. Out of 51 evaluable patients, the overall response rate was $64.7 \%$ (95\% CI, $51.6 \%-77.8 \%$ ) including one complete response. With a median follow-up period of 8.4 months, the median progression-free survival was 6.2 months and median overall survival was not reached. The relative dose intensities of docetaxel and S-1 were $91 \%$ and $85 \%$, respectively. The most common grade $3 / 4$ toxicities were neutropenia $(27.5 \%)$ and febrile neutropenia $(17.6 \%)$. Grade 3 nonhematological toxicities included infection without neutropenia (21.6\%), fatigue $(9.8 \%)$, liver enzyme elevation (7.8\%), constipation (5.9\%), and diarrhea $(3.9 \%)$.

A phase II study of paclitaxel plus S-1 as first-line therapy in patients with advanced or relapsed gastric cancer was conducted as a multicenter study under the auspices of the Korean Cancer Study Group and the result was reported at the 2007 American Society of Clinical Oncology annual meeting [43]. Patients received $70 \mathrm{mg} / \mathrm{m}^{2}$ of paclitaxel administered intravenously on days 1 and 8 and oral S-1 administered at $35 \mathrm{mg} / \mathrm{m}^{2}$ twice daily on days $1-14$ of each 3-week cycle. A total of 56 patients were enrolled. Out of 53 evaluable patients, 1 had a complete response (2\%), and 25 had partial responses (47\%), giving an overall response rate of $49 \%(26 / 56)$. With a median follow-up period of 9.6 months, the median progression-free survival was 7.7 months and median survival was 14.6 months. The relative dose intensities of paclitaxel and S-1 were $93 \%$ for each. The most common cause of a delayed cycle was neutropenia and the most common cause of dose reduction was diarrhea. The most common grade $3 / 4$ toxicities were neutropenia (19\%) and febrile neutropenia $(5 \%)$. Most nonhematological toxicities were of mild to moderate intensity. Grade 3 nonhematological toxicities were observed in $10 \%$ of the patients (diarrhea in $4 \%$, stomatitis in $4 \%$, and anorexia in $2 \%$ ). In this study, paclitaxel and S-1 combination chemotherapy showed significant activity with manageable and tolerable toxicities in patients with advanced gastric cancer.

\section{Future prospects for combination chemotherapy with S-1 and taxanes}

Several studies, from Europe, the United States, Japan, and Korea, have assessed docetaxel monotherapy in the treatment of advanced gastric cancer, with generally consistent results. While four studies from Europe and the United States administered docetaxel at a dosage of $100 \mathrm{mg} / \mathrm{m}^{2}$ [44-47], the Japanese studies used docetaxel at $60 \mathrm{mg} / \mathrm{m}^{2}[48,49]$ and a Korean phase II study used a dose of $75 \mathrm{mg} / \mathrm{m}^{2}$ [16]; in these seven studies, the response rate varied in a narrow range, from $17 \%$ to $24 \%$, despite the varying dosages.

Two phase I studies of combination therapy with docetaxel and S-1 were conducted in Japan (Table 1). 
One study (Yoshida et al. [37]) adopted an every-3week schedule with S-1 administration for 2 weeks and the other study used an every-4-week schedule of S-1 with 2 weeks on and 2 weeks off [36]. In these two studies, the RD of docetaxel was $40 \mathrm{mg} / \mathrm{m}^{2}$ every 3 or 4 weeks in combination with S- 1 administered at a fixed dose of $40 \mathrm{mg} / \mathrm{m}^{2}$ twice daily on days $1-14$. Considering the definition of DLTs in the study by Yoshida et al. [37], there is a possibility that the reported RD may have been a suboptimal one, because most grade 4 neutropenia lasting for less than 7 days is usually considered to be manageable. Actually, Yoshida et al. [37] reported that the MTD was reached at level 2 (docetaxel $50 \mathrm{mg} / \mathrm{m}^{2}$ plus oral S-1 administered at a fixed dose of $40 \mathrm{mg} / \mathrm{m}^{2}$ twice daily on days $1-14$ of each 3 -week cycle) in three out of six patients, and grade 4 neutropenia was the DLT in two patients. In the other Japanese phase I study of docetaxel plus S-1 [36], the DLTs were defined as grade 4 neutropenia lasting for 5 days or longer; grade 4 neutropenia with fever; grade 4 thrombocytopenia; grade 3/4 nonhematological toxicities other than nausea/vomiting, anorexia, and general fatigue; and any grade 4 hematological toxicity during S-1 administration. The numbers of patients showing DLTs in this study were: one patient with grade 3 infection associated with grade 3 neutropenia and two patients with grade 4 neutropenia during S- 1 administration at dose level 1 (docetaxel $50 \mathrm{mg} / \mathrm{m}^{2}$ plus oral S-1 administered at a fixed dose of $40 \mathrm{mg} / \mathrm{m}^{2}$ twice daily on days 1-14 of each 4-week cycle). The results from these two phase I studies suggested that the development of grade 4 neutropenia was frequent at the dose level of docetaxel $50 \mathrm{mg} / \mathrm{m}^{2}$ plus oral S-1 administered at a fixed dose of $40 \mathrm{mg} / \mathrm{m}^{2}$ twice daily on days 1-14 of a 3- or 4-week cycle, but the duration of severe neutropenia was not specified.

According to the study by Kim et al. [39], carried out in patients with advanced gastric cancer, only two out of five patients with DLT had DLT related to significant neutropenia (one patient with grade 4 neutropenia for more than 7 days and one patient with grade 3 febrile neutropenia). Also, six patients, who were enrolled at the dose level of docetaxel $50 \mathrm{mg} / \mathrm{m}^{2}$ plus S-1 $40 \mathrm{mg} / \mathrm{m}^{2}$ twice daily on days $1-14$ of each 3 -week cycle, tolerated 39 cycles of treatment without dose modification. The mean dose intensity of docetaxel was $15.5 \mathrm{mg} / \mathrm{m}^{2}$ per week, which supports the idea that docetaxel $50 \mathrm{mg} / \mathrm{m}^{2}$ plus S- $140 \mathrm{mg} / \mathrm{m}^{2}$ twice daily on days 1-14 of each 3-week cycle would be a tolerable dosage in this patient group. A phase I/II study conducted in Korea reported that the optimal docetaxel dosage would be $60-75 \mathrm{mg} / \mathrm{m}^{2}$ plus S-1 $40 \mathrm{mg} / \mathrm{m}^{2}$ twice daily on days 1-14 of each 3-week cycle [40]. In a phase I study, which adopted weekly docetaxel administration with S-1 daily on days 1-14 of each 3-week cycle, the recommended dose intensity of docetaxel was $23.3 \mathrm{mg} /$ $\mathrm{m}^{2}$ per week. However, grade 4 neutropenia still developed in two of four patients at the dose level of docetaxel $40 \mathrm{mg} / \mathrm{m}^{2}$ plus S- $140 \mathrm{mg} / \mathrm{m}^{2}$ twice daily on days 1-14 of each 3-week cycle; clinical efficacy was noted at this dose level. Hence, Korean investigators agreed to adopt docetaxel $40 \mathrm{mg} / \mathrm{m}^{2}$ on day 1 plus S-1 $40 \mathrm{mg} / \mathrm{m}^{2}$ twice daily on days $1-14$ of each 3-week cycle, as an experimental arm to be compared with S-1 $40 \mathrm{mg} /$ $\mathrm{m}^{2}$ twice daily monotreatment on days $1-28$, every 6 weeks, in a phase III study in patients with advanced gastric cancer. We are awaiting the final result of this phase III study comparing S-1 alone to docetaxel plus S-1 in, patients with advanced gastric cancer in Japan and Korea (in which patient enrollment has just finished), to confirm the advantage of docetaxel in terms of response and survival.

The clinical efficacy of combination chemotherapy with S-1 and taxanes shows that this combination is highly active. Two phase I/II studies of docetaxel plus S-1 combination chemotherapy, from Japan and Korea, reported a response rate of $45.7 \%$ (21/46), with two complete responses [36] and a response rate of $43.3 \%$ [40], respectively (Table 1 ). Yoshida et al. [38] reported a response rate of $56.3 \%(27 / 48)$ with docetaxel $40 \mathrm{mg} /$ $\mathrm{m}^{2}$ on day 1 plus S-1 $40 \mathrm{mg} / \mathrm{m}^{2}$ twice daily on days $1-14$ of each 3-week cycle, which was similar to our study findings [39]. Also, in a phase II study of paclitaxel plus S-1 as first-line therapy in patients with advanced or relapsed gastric cancer [43], the response rate was $46 \%$ (26/56), including one complete response. These response rates are the most favorable of those that have been reported in the treatment of advanced gastric cancer. Although the determination of efficacy was not the primary purpose of phase I studies, and the number of patients was small, it is highly notable that the response rate of the docetaxel plus S-1 combination chemotherapy was impressively high. The overall objective response rates in Korean phase I studies using an S-1 plus docetaxel combination were $69.2 \%(95 \% \mathrm{CI}$, $44.1 \%-94.3 \%$ ) [39] and $65.5 \%$ (95\% CI, $48.2 \%-82.8 \%)$ [41].

The most frequent significant toxicities in taxane plus S-1 combination chemotherapy were neutropenia and febrile neutropenia. However, the nonhematological toxicities were of mild to moderate intensity. In clinical practice, nonhematological toxicities are more difficult to manage than uncomplicated neutropenia, but if the nonhematological toxicities are mild to moderate, patients can tolerate chemotherapy of long duration without delay or interruption of treatment.

We conclude that a taxane plus S-1 combination regimen could be a new standard regimen for advanced gastric cancer, given its significant activity and favorable toxicity pattern. 


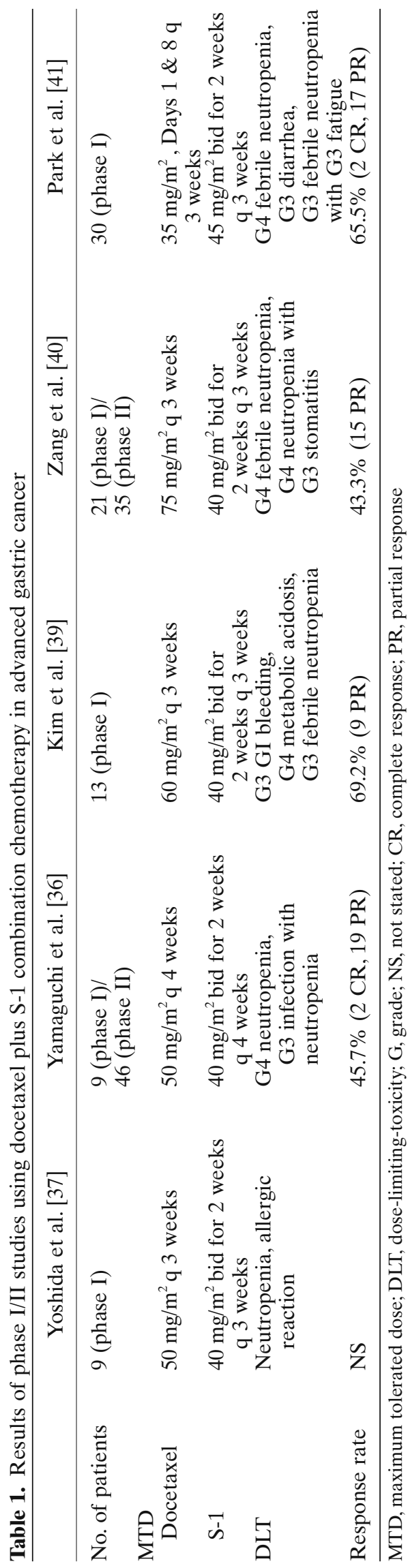

\section{References}

1. Jemal A, Siegel R, Ward E, Murray T, Xu J, Thun MJ. Cancer statistics, 2007. CA Cancer J Clin 2007:57:43-66.

2. Shin H-R, Won Y-J, Jung K-W, Kong H-J, Yim S-H, Lee J-K, et al. Nationwide cancer incidence in Korea, 1999-2001; First result using the National Cancer Incidence Database. Cancer Res Treat 2005;37:325-31.

3. Kamangar F, Dores GM, Anderson WF. Patterns of cancer incidence, mortality, and prevalence across five continents: defining priorities to reduce cancer disparities in different geographic regions of the world. J Clin Oncol 2006;24:2137-50.

4. Pyrhonen S, Kuitunen T, Nyandoto P, Kouri M. Randomised comparison of fluorouracil, epidoxorubicin and methotrexate (FEMTX) plus supportive care with supportive care alone in patients with non-resec gastric cancer. Br J Cancer 1995;71: 587-91.

5. Glimelius B, Ekstrom K, Hoffman K, Graf W, Sjoden PO, Haglund U, et al. Randomized comparison between chemotherapy plus best supportive care with best supportive care in advanced gastric cancer. Ann Oncol 1997;8:163-8.

6. Glimelius B, Hoffman K, Haglund U, Nyren O, Sjoden PO. Initial or delayed chemotherapy with best supportive care in advanced gastric cancer. Ann Oncol 1994;5:189-90.

7. Kim YH, Shin SW, Kim BS, Kim JH, Kim JG, Mok YJ, et al. Paclitaxel, 5-fluorouracil, and cisplatin combination chemotherapy for the treatment of advanced gastric carcinoma. Cancer 1999;85:295-301.

8. Im CK, Jeung HC, Rha SY, Yoo NC, Noh SH, Roh JK, et al. A phase II study of paclitaxel combined with infusional 5fluorouracil and low-dose leucovorin for advanced gastric cancer. Cancer Chemother Pharmacol 2008;61:315-21.

9. Kim JG, Sohn SK, Song HS, Kwon KY, Do YR, Lee KH, et al. Multicenter phase II study of weekly paclitaxel plus cisplatin combination chemotherapy in patients with advanced gastric cancer. Cancer Chemother Pharmacol 2007;

10. Lee KW, Im SA, Yun T, Song EK, Na I, Shin H, et al. Phase II trial of low-dose paclitaxel and cisplatin in patients with advanced gastric cancer. Jpn J Clin Oncol 2005;35:720-6.

11. Chang HM, Kim TW, Ryu BY, Choi SJ, Park YH, Lee JS, et al. Phase II study of paclitaxel and carboplatin in advanced gastric cancer previously treated with 5-fluorouracil and platinum. Jpn J Clin Oncol 2005;35:251-5.

12. Park SH, Lee WK, Chung M, Lee Y, Han SH, Bang SM, et al. Paclitaxel versus docetaxel for advanced gastric cancer: a randomized phase II trial in combination with infusional 5-fluorouracil. Anticancer Drugs 2006;17:225-9.

13. Pazdur R, Kudelka AP, Kavanagh JJ, Cohen PR, Raber MN. The taxoids: paclitaxel (Taxol) and docetaxel (Taxotere). Cancer Treat Rev 1993;19:351-86.

14. Diaz JF, Andreu JM. Assembly of purified GDP-tubulin into microtubules induced by taxol and taxotere: reversibility, ligand stoichiometry, and competition. Biochemistry 1993;32:2747-55.

15. Di Cosimo S, Ferretti G, Fazio N, Silvestris N, Carlini P, Alimonti A, et al. Docetaxel in advanced gastric cancer-review of the main clinical trials. Acta Oncol 2003;42:693-700.

16. Bang YJ, Kang WK, Kang YK, Kim HC, Jacques C, Zuber E, et al. Docetaxel $75 \mathrm{mg} / \mathrm{m}(2)$ is active and well tolerated in patients with metastatic or recurrent gastric cancer: a phase II trial. Jpn J Clin Oncol 2002;32:248-54.

17. Lee JL, Ryu MH, Chang HM, Kim TW, Yook JH, Oh ST, et al. A phase II study of docetaxel as salvage chemotherapy in advanced gastric cancer after failure of fluoropyrimidine and platinum combination chemotherapy. Cancer Chemother Pharmacol 2007;

18. Park SH, Kang WK, Lee HR, Park J, Lee KE, Lee SH, et al. Docetaxel plus cisplatin as second-line therapy in metastatic or recurrent advanced gastric cancer progressing on 5-fluorouracilbased regimen. Am J Clin Oncol 2004;27:477-80. 
19. Park KW, Ahn JS, Park YS, Lee J, Kang JH, Park JO, et al. Phase II study of docetaxel and cisplatin combination chemotherapy in metastatic gastric cancer. Cancer Chemother Pharmacol 2007; 59:17-21.

20. Kim H, Park JH, Bang SJ, Kim DH, Cho HR, Kim GY, et al. A phase II study of docetaxel and cisplatin in patients with gastric cancer recurring after or progressing during 5-FU/platinum treatment. Jpn J Clin Oncol 2005;35:727-32.

21. Jeung HC, Rha SY, Kim YT, Noh SH, Roh JK, Chung HC. A phase II study of infusional 5-fluorouracil and low-dose leucovorin with docetaxel for advanced gastric cancer. Oncology 2006; 70:63-70.

22. Chun JH, Kim HK, Lee JS, Choi JY, Hwangbo B, Lee HG, et al. Weekly docetaxel in combination with capecitabine in patients with metastatic gastric cancer. Am J Clin Oncol 2005;28:188-94.

23. Park YH, Ryoo BY, Choi SJ, Kim HT. A phase II study of capecitabine and docetaxel combination chemotherapy in patients with advanced gastric cancer. Br J Cancer 2004;90:1329-33.

24. Kim JG, Sohn SK, Kim DH, Baek JH, Sung WJ, Park JY, et al. Phase II study of docetaxel and capecitabine in patients with metastatic or recurrent gastric cancer. Oncology 2005;68:1905.

25. Van Cutsem E, Moiseyenko VM, Tjulandin S, Majlis A, Constenla M, Boni C, et al. Phase III study of docetaxel and cisplatin plus fluorouracil compared with cisplatin and fluorouracil as first-line therapy for advanced gastric cancer: a report of the V325 Study Group. J Clin Oncol 2006;24:4991-7.

26. Shirasaka T, Shimamato Y, Ohshimo H, Yamaguchi M, Kato T, Yonekura K, et al. Development of a novel form of an oral 5fluorouracil derivative (S-1) directed to the potentiation of the tumor selective cytotoxicity of 5-fluorouracil by two biochemical modulators. Anticancer Drugs 1996;7:548-57.

27. Sakata Y, Ohtsu A, Horikoshi N, Sugimachi K, Mitachi Y, Taguchi T. Late phase II study of novel oral fluoropyrimidine anticancer drug S-1 (1 M tegafur- $0.4 \mathrm{M}$ gimestat-1 M otastat potassium) in advanced gastric cancer patients. Eur J Cancer 1998;34:1715-20.

28. Koizumi W, Kurihara M, Nakano S, Hasegawa K. Phase II study of S-1, a novel oral derivative of 5-fluorouracil, in advanced gastric cancer. For the S-1 Cooperative Gastric Cancer Study Group. Oncology 2000;58:191-7.

29. Chollet P, Schoffski P, Weigang-Kohler K, Schellens JH, Cure H, Pavlidis N, et al. Phase II trial with S-1 in chemotherapy-naive patients with gastric cancer. A trial performed by the EORTC Early Clinical Studies Group (ECSG). Eur J Cancer 2003;39: 1264-70.

30. Jeung HC, Rha SY, Kim HK, Lim HY, Kim S, Kim SY, et al. Multi-institutional phase II study of S-1 monotherapy in advanced gastric cancer with pharmacokinetic and pharmacogenomic evaluations. Oncologist 2007;12:543-54.

31. Lee JL, Kang HJ, Kang YK, Ryu MH, Chang HM, Kim TW, et al. Phase I/II study of 3-week combination of S-1 and cisplatin chemotherapy for metastatic or recurrent gastric cancer. Cancer Chemother Pharmacol 2008;61:37-45.

32. Takahashi I, Emi Y, Kakeji Y, Uchida J, Fukushima M, Maehara Y. Increased antitumor activity in combined treatment TS-1 and docetaxel. A preclinical study using gastric cancer xenografts. Oncology 2005;68:130-7.

33. Wada Y, Yoshida K, Suzuki T, Mizuiri H, Konishi K, Ukon K, et al. Synergistic effects of docetaxel and S-1 by modulating the expression of metabolic enzymes of 5-fluorouracil in human gastric cancer cell lines. Int J Cancer 2006;119:783-91.

34. Rino Y, Takanashi Y, Yukawa N, Saeki H, Wada H, Kanari M, et al. A phase I study of bi-weekly combination therapy with S-1 and docetaxel for advanced or recurrent gastric cancer. Anticancer Res 2006;26:1455-62.
35. Takahashi I, Emi Y, Kakeji Y, Tokunaga E, Ushiro S, Oki E, et al. Phase I study of S-1 and biweekly docetaxel combination chemotherapy for advanced and recurrent gastric cancer. Oncol Rep 2006;15:849-54.

36. Yamaguchi K, Shimamura T, Hyodo I, Koizumi W, Doi T, Narahara H, et al. Phase I/II study of docetaxel and S-1 in patients with advanced gastric cancer. Br J Cancer 2006;94:1803-8.

37. Yoshida K, Hirabayashi N, Takiyama W, Ninomiya M, Takakura $\mathrm{N}$, Sakamoto J, et al. Phase I study of combination therapy with S-1 and docetaxel (TXT) for advanced or recurrent gastric cancer. Anticancer Res 2004;24:1843-51.

38. Yoshida K, Ninomiya M, Takakura N, Hirabayashi N, Takiyama W, Sato Y, et al. Phase II study of docetaxel and S-1 combination therapy for advanced or recurrent gastric cancer. Clin Cancer Res 2006;12:3402-7.

39. Kim H, Kim YH, Shim BY, Shin SW, Moon H. Phase I study for the escalation of docetaxel with fixed doses of TS1 in advanced gastric cancer. 2006 Gastrointestinal Cancers Symposium; 2006 January 26-28; San Francisco, CA, USA.

40. Zang DY, Song HH, Kwon JH, Jung JY, Kim HJ, Kim JH, et al. Phase I/II trial with docetaxel and S-1 for patients with advanced recurrent gastric cancer. Ann Oncol 2006;17(Suppl 9): abstract no 1097P.

41. Park SR, Yu MS, Kim CG, Choi IJ, Lee JS, Kim YW, et al. A phase I study of S-1 plus weekly docetaxel in patients with metastatic gastric cancer (abstract). J Clin Oncol 2006;24:14005.

42. Park SR, Park MS, Kim NK, Lee JY, Kim CG, Choi IJ, et al. A phase II study of S-1 plus weekly docetaxel in patients with metastatic gastric carcinoma. American Association for Cancer Research Annual Meeting Proceedings; 2007 April 14-18; Los Angeles, CA, USA.

43. Lee JJ, Kim SY, Chung HC, Lee KH, Song HS, Woo IS, et al. A multi-center phase II study of S-1 plus paclitaxel as first-line therapy in patients with advanced or relapsed gastric cancer (abstract). J Clin Oncol 2007;25:4634.

44. Sulkes A, Smyth J, Sessa C, Dirix LY, Vermorken JB, Kaye S, et al. Docetaxel (Taxotere) in advanced gastric cancer: results of a phase II clinical trial. EORTC Early Clinical Trials Group. Br J Cancer 1994;70:380-3.

45. Einzig AI, Neuberg D, Remick SC, Karp DD, O'Dwyer PJ, Stewart JA, et al. Phase II trial of docetaxel (Taxotere) in patients with adenocarcinoma of the upper gastrointestinal tract previously untreated with cytotoxic chemotherapy: the Eastern Cooperative Oncology Group (ECOG) results of protocol E1293. Med Oncol 1996;13:87-93.

46. Giuliani F, Gebbia V, De Vita F, Maiello E, Di Bisceglie M, Catalano G, et al. Docetaxel as salvage therapy in advanced gastric cancer: a phase II study of the Gruppo Oncologico Italia Meridionale (G.O.I.M.). Anticancer Res 2003;23:4219-22.

47. Mavroudis D, Kourousis C, Androulakis N, Kalbakis K, Agelaki S, Kakolyris S, et al. Frontline treatment of advanced gastric cancer with docetaxel and granulocyte colony-stimulating factor (G-CSF): a phase II trial. Am J Clin Oncol 2000;23:341-4.

48. Mai M, Sakata Y, Kanamaru R, Kurihara M, Suminaga M, Ota J, et al. A late phase II clinical study of RP56976 (docetaxel) in patients with advanced or recurrent gastric cancer: a Japanese Cooperative Study Group trial (group B) (in Japanese). Gan To Kagaku Ryoho 1999;26:487-96.

49. Taguchi T, Sakata Y, Kanamaru R, Kurihara M, Suminaga M, Ota J, et al. Late phase II clinical study of RP56976 (docetaxel) in patients with advanced/recurrent gastric cancer: a Japanese Cooperative Study Group trial (group A) (in Japanese). Gan To Kagaku Ryoho 1998;25:1915-24. 